\title{
Case Report Varicocele and a Vascular Tumor in the Testis
}

\author{
Christoph Kraft ${ }^{1}$ and Jan Janzen ${ }^{2}$ \\ ${ }^{1}$ Urologie, Baslerstrasse 66, 4600 Olten, Switzerland \\ ${ }^{2}$ Histopathologie, Worbstrasse 312, 3073 Gümligen bei Bern, Switzerland \\ Correspondence should be addressed to Jan Janzen; info@janlab.ch
}

Received 19 May 2013; Accepted 1 July 2013

Academic Editors: G. Lombardi and A. Marte

Copyright @ 2013 C. Kraft and J. Janzen. This is an open access article distributed under the Creative Commons Attribution License, which permits unrestricted use, distribution, and reproduction in any medium, provided the original work is properly cited.

A 50-year-old man presented a rare morphological constellation: a left-sided varicocele (stage 3) and a vascular rich Sertoli cell tumor.

\section{Introduction}

It is well known that varicocele leads to circulatory disturbances, testicular atrophy (shrinking), seminiferous tubule sclerosis, vessels degenerative changes, and abnormalities of Leydig, Sertoli, and germ cells $[1,2]$. We have observed a high-grade varicocele in association with a testicular vascular tumor.

\section{Case Presentation}

A 50-year-old man came to the urologist and presented a painful mass in the left scrotum. Clinically, a high-grade varicocele (stage 3 ) and a low testicular volume were found (Figure 1). Furthermore, a tumor in the upper pole area of the left testicle was observed. All tumor markers were negative; there were no symptoms of a renal cell carcinoma or nutcracker syndrome. Because of the low testicular volume, a left inguinal orchiectomy without intraoperative histopathological diagnosis (frozen section) was performed.

Macroscopically, an abnormal dilation of the plexus pampiniformis and vessel mass measuring $50 \mathrm{~mm}$ in diameter were found. Left testicle measured $38 \times 30 \times 15 \mathrm{~mm}$, and a $12 \times 8 \times 6 \mathrm{~mm}$ grey white solid tumor was seen (Figures 2 and 3). Rete testis, epididymis, and spermatic cord were inconspiciuous.

Microscopically, abnormal venous vessels in the plexus pampiniformis characterised by a severe leiomyomatous hyperplasia with incorporated nerve fibers were found. The lumen of the veins varied between 15 and $25 \mathrm{~mm}$. Venous valves were absent. The testicular tumor had two microscopic patterns:

(i) vascular pattern in $70 \%$ of the tumor area: thick-wall vessels with CD34 expression and epithelioid cells,

(ii) tubular pattern in $30 \%$ of the tumor area: hyalinised Sertoli cells with cytokeratin 18 expression (Figures 4 and 5).

Overall, a low proliferation rate (1 Mitosis/10 HPF), MIB1 (Ki67) in 3-5\% of the tumor cells were detected; neither lymph nor hemangiosis carcinomatosa were observed. Adjacent testicular parenchyma showed a complete and arrested spermatogenesis, and a testicular intraepithelial neoplasia was excluded by immunohistochemistry (PLAP negative). We propose to classify this non-malignant tumor as a vascular rich Sertoli cell tumor of the testis.

\section{Discussion}

Morphologically, our case had two distinct entities-a highgrade varicocele and a vascular tumor of the testis. The benign tumor consists of vascular and tubular components with a clear dominance of vascular differentiated cells. To our knowledge, such a case has not been published yet in this particular clinical constellation. On one side, it could be that the existence of varicocele and benign tumor in the same testis is due to chance. On the other side, a long-lasting irregular blood circulation of the testis induced by varicocele (stage 3 ) could play an important role in the aetiopathogenesis [1]. 


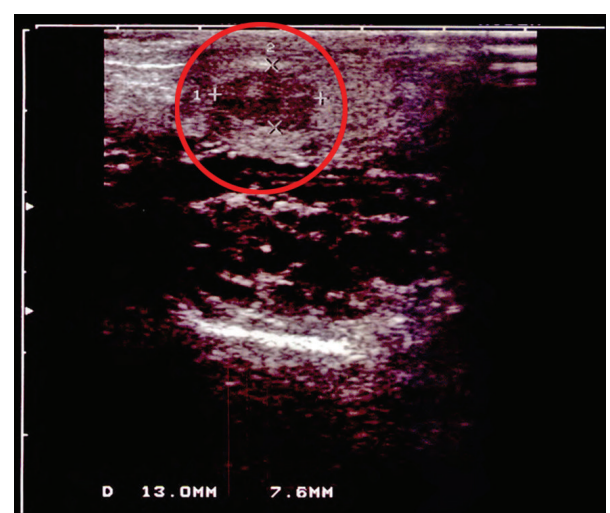

FIGURE 1: Tumor (red circle) and high-grade varicocele in sonography.

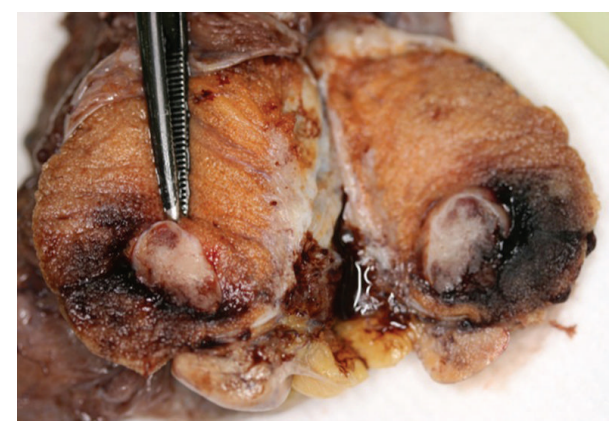

Figure 2: Macroscopic aspects of the benign testicular tumor.

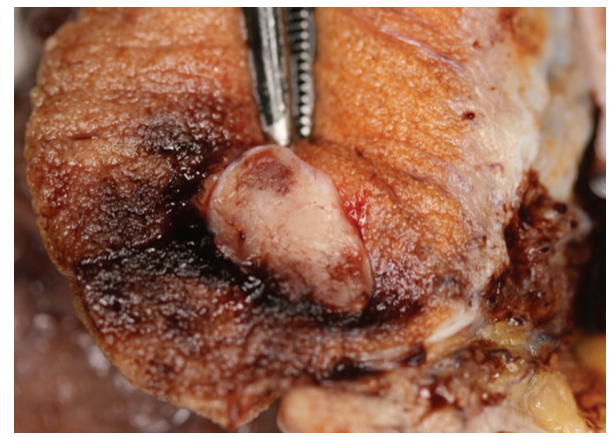

FIGURE 3: Vascular testicular tumor, measuring $12 \mathrm{~mm}$ in diameter.

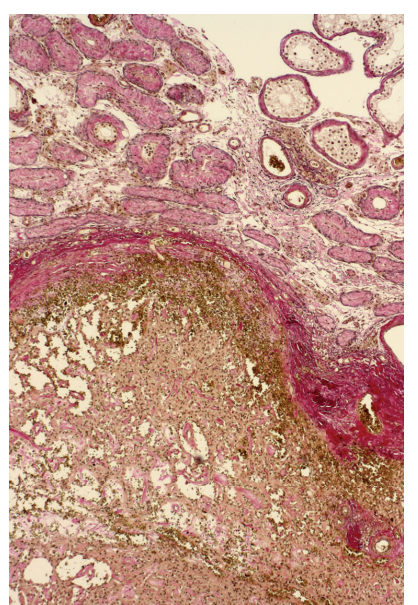

FIGURE 4: Microscopic aspects: benign vascular tumor and testicular parenchyma.

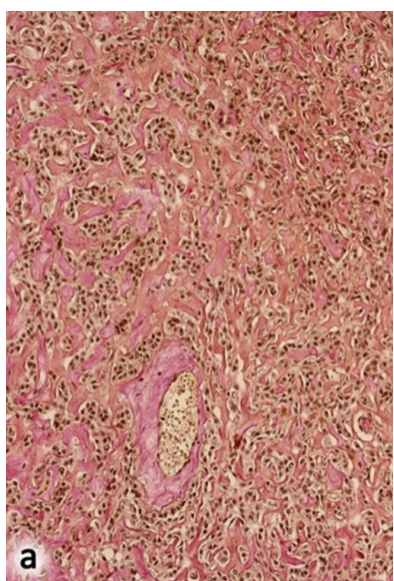

(a)

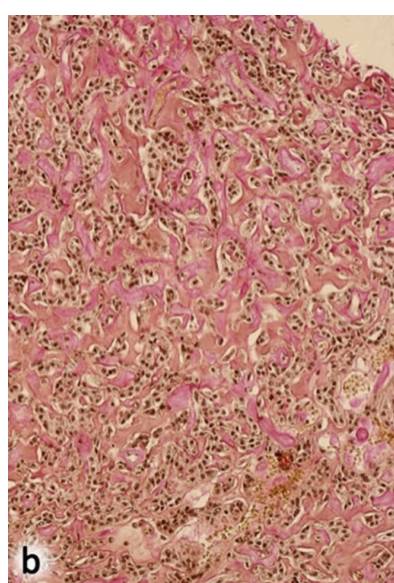

(b)
FIGURE 5: Microscopic aspects: Sertoli cells (a) and vascular components (b).

Furthermore, the higher temperature of the testis induced by varicocele should be considered as a causative factor in the tumorigenesis [3].

The clinical take-home message of the case report is as follows: a high-grade varicocele can occur with a benign vascular tumor of the testis.

\section{Authors' Contribution}

Dr. med. Christoph Kraft performed the surgery and was in charge of patient care. Dr. med. Jan Janzen carried out the histopathological examination.

\section{Acknowledgment}

The authors thank Professor Dr. med. Jürgen Pannek, Dr. med. Konrad Göcking, Dr. med. Peter Bartel, and Tanja Schneider for their help.

\section{References}

[1] J. Chakraborty, A. P. Hikim, and J. S. Jhunjhunwala, "Stagnation of blood in the microcirculatory vessels in the testes of men with varicocele," Journal of Andrology, vol. 6, no. 2, pp. 117-126, 1985.

[2] D. A. Paduch and S. J. Skoog, "Current management of adolescent varicocele," Reviews in Urology, vol. 3, pp. 120-133, 2001.

[3] Z.-F. Zhang, J. E. Vena, M. Zielezny et al., "Occupational exposure to extreme temperature and risk of testicular cancer," Archives of Environmental Health, vol. 50, no. 1, pp. 13-18, 1995. 


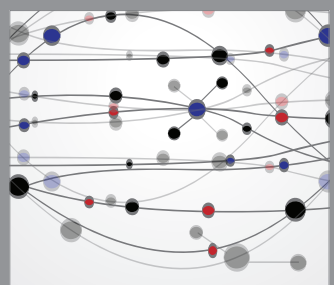

The Scientific World Journal
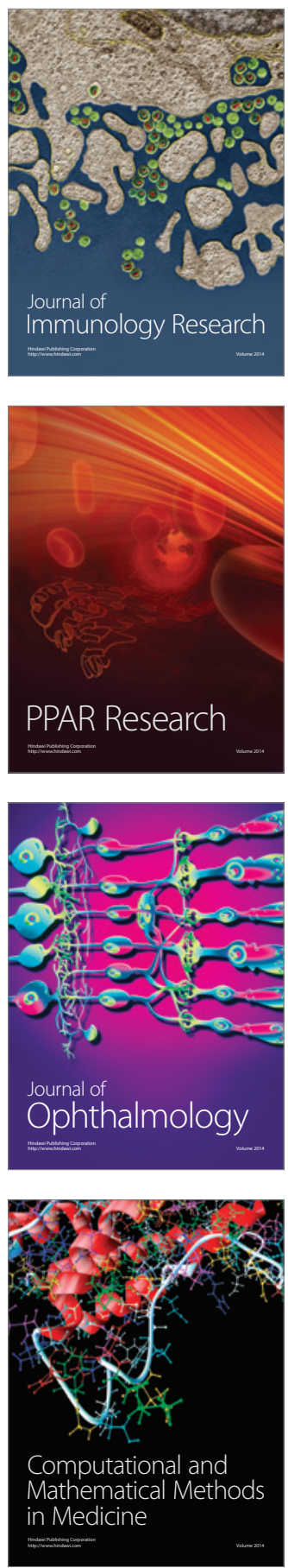

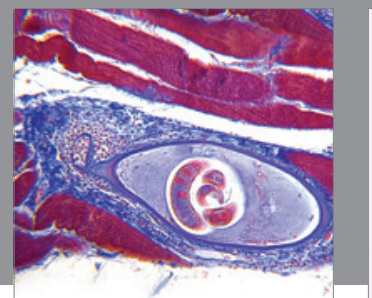

Gastroenterology

Research and Practice
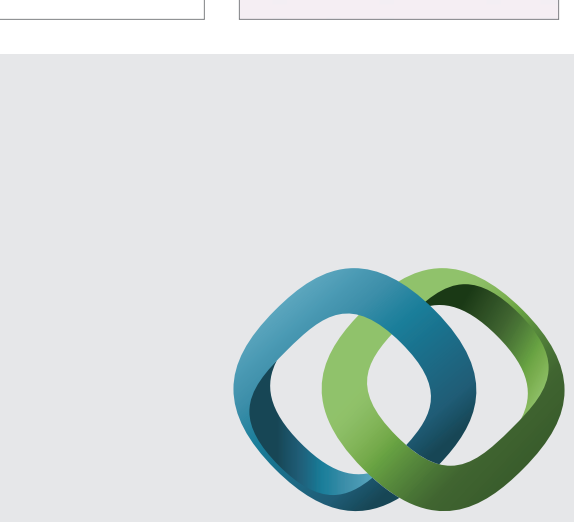

\section{Hindawi}

Submit your manuscripts at

http://www.hindawi.com
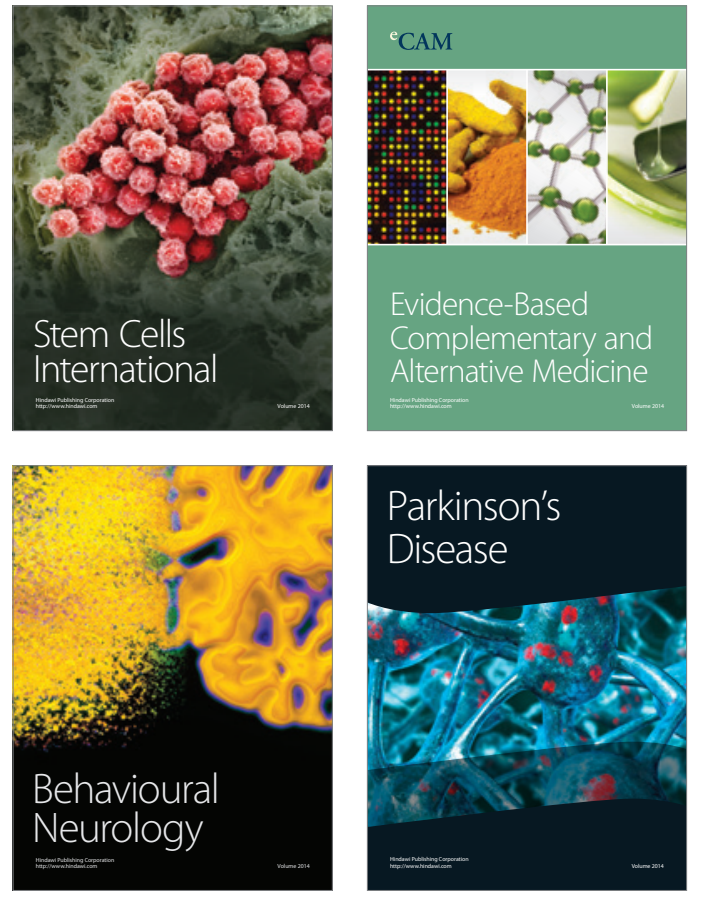
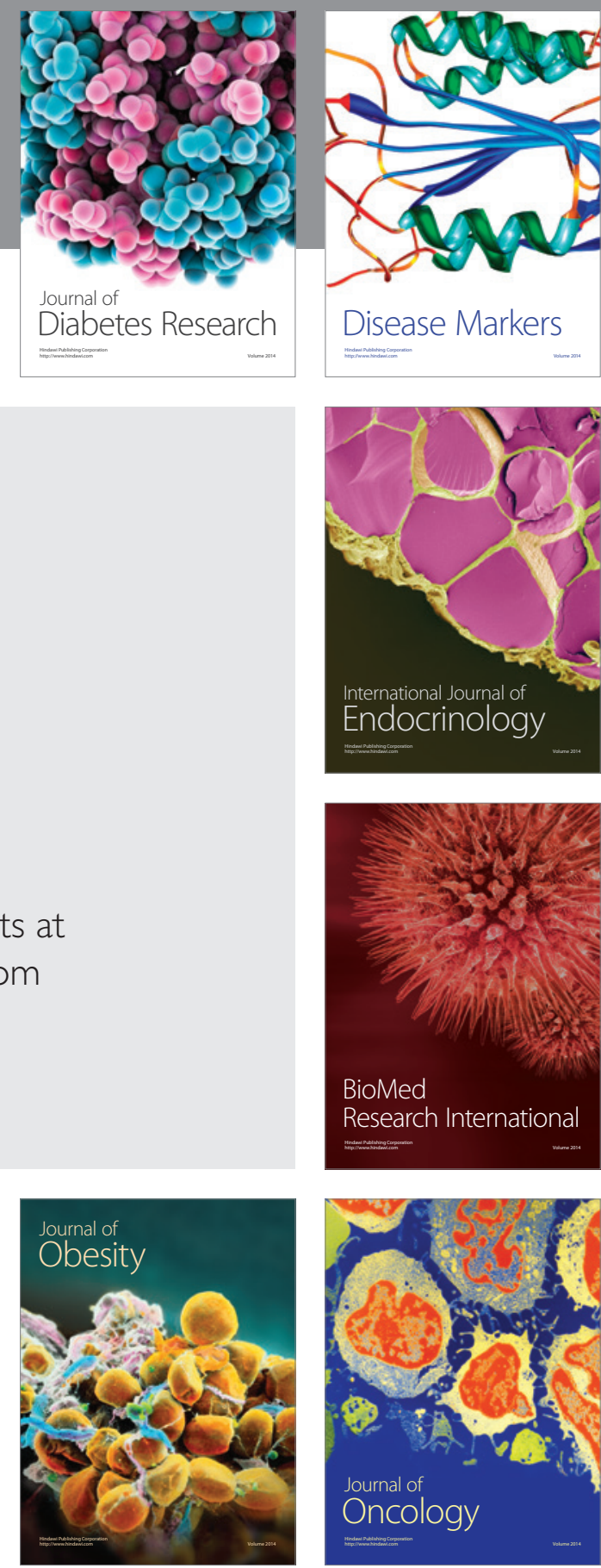

Disease Markers
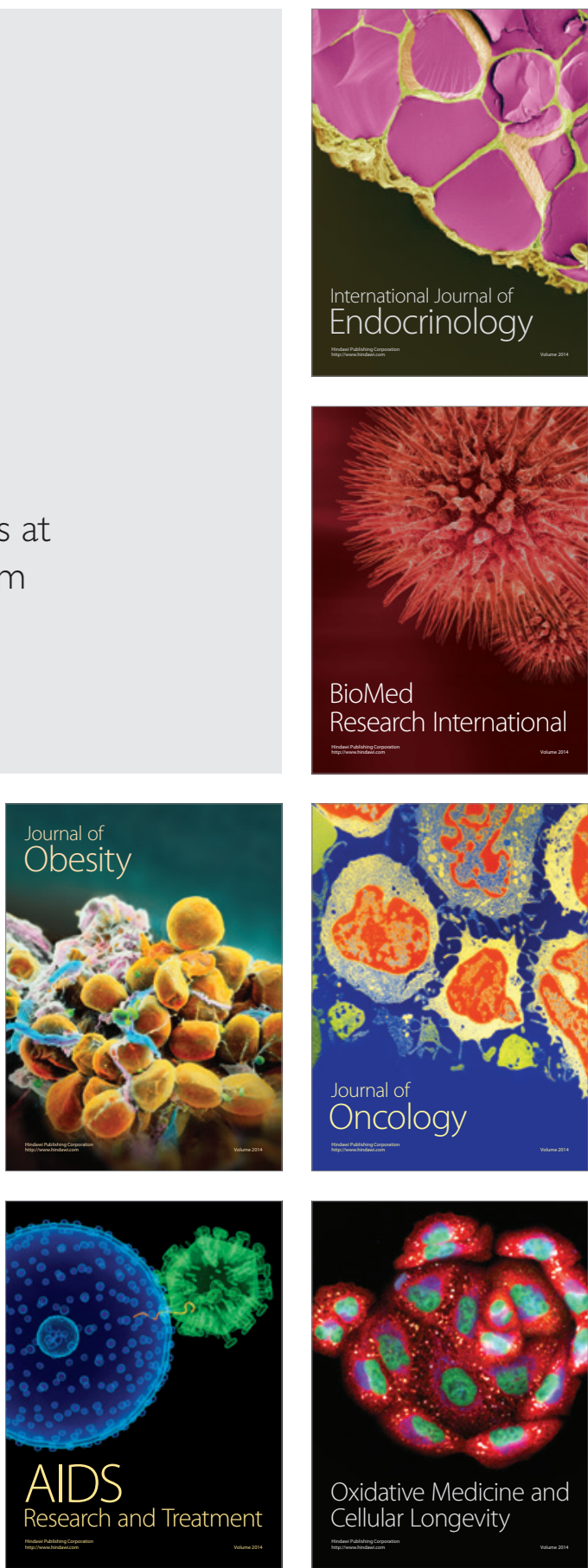